\title{
Madres Latinas
}

Amigas

\section{Moms Group Meets Needs of Spanish-Speaking Community}

ELANME T.PÉBREZ



Preparing the soil at the Patchogue Community Garden, 2012.
$\mathrm{T}$ he Patchogue-Medford Library's goal is to reach the needs of the community by providing informational resources through cultural, educational, and recreational venues to all, and outreach is one way we strive to do this.

We use our staff time and energy to reassure visitors that everyone is welcome to participate in the programs, with the hopes that they will share and expand on their library experiences with others. Programs help promote self-esteem to become better parents, spouses, and friends and create a support system to benefit everyone in the community.

One such program is Madres Latinas Amigas. The group originated more than four years ago with a patron who felt she needed to reach out to other Spanish-speaking patrons from numerous Latin American countries who were trying to navigate the intricacies of the library. Her enthusiasm reached many patrons eager to become library users, and she became our library advocate.

Part of our library's outreach is visiting elementary schools and speaking to parents on open house and English as a Second Language (ESL) nights. A bilingual librarian is assigned to speak to parents and inform them of the library resources available.

Smiles and questions always follow, about how to obtain the most important passport to the library world-the library card. Through the use of translators and library personnel, our quest has expanded as we have reached our community through flyers, word of mouth, and local Spanish radio.

It was through these meetings that our library advocate approached library personnel, and the idea of the Madres Latinas Amigos was born. That advocate is now a part-time employee, working in all other areas of the library as well.

The group includes moms from Latin American countries, especially Ecuador, and has included a mom from Ireland and another from India. The Irish woman is married to a Spanishspeaking person, and she wanted to have the opportunity to speak the language and become involved in the community. The Indian mother made a connection with the moms by sharing the difficulties of learning a new language and seeking assistance from library personnel. The moms who spoke some English were eager to help her and her son feel comfortable in the community.

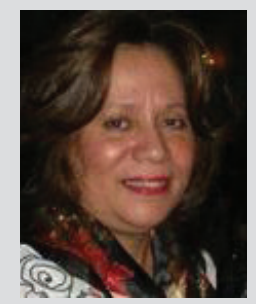

Elaine T. Pérez is a Children's Librarian at Patchogue-Medford (NY) Library. 


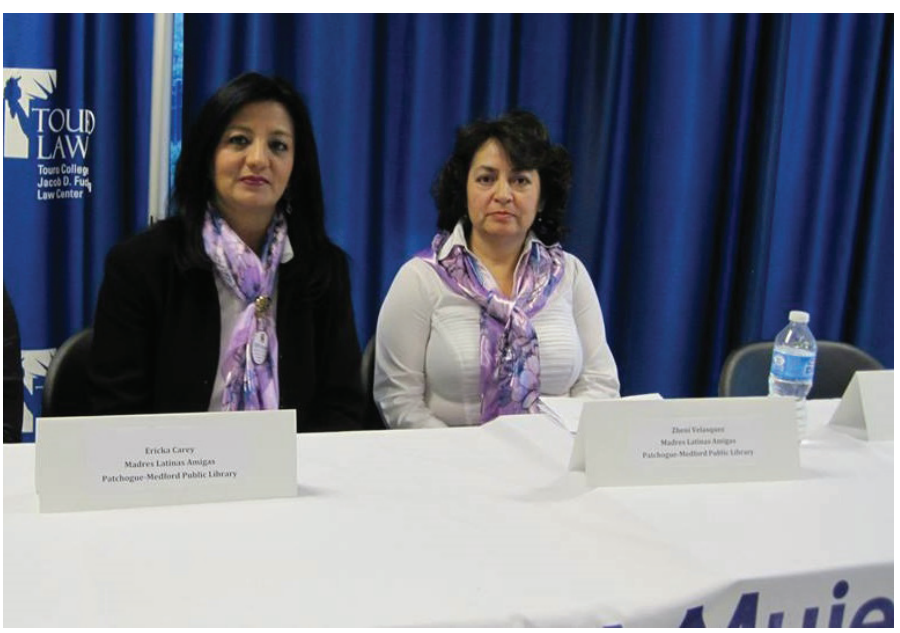

Madres co-leaders Ericka Carey and Zheni Velasquez-Panelists at Sepa Mujer Latinas Conference en Acción-December 2013

Since the inception of the program, patrons have requested to meet together and discuss their concerns. It is an opportunity to discuss the many issues they are experiencing, especially when they may not have an outlet through which to pose questions and receive answers.

The group has grown in leaps and bounds with growing pains along the way. For example, one issue we faced was figuring out child care. Many moms did not have babysitters or family nearby to care for their children while attending the meetings. We were able to hire another Spanish-speaking, part-time librarian who conducts storytimes during our meeting times. And the group now has an additional moderator who works with our library advocate on Monday evenings. Both moderators are supervised by a full-time bilingual librarian. Two library pages assist with storytimes, which usually draw fifteen to thirty children.

Our core group includes fifteen to twenty moms; on some occasions, we have had as many as fifty attend pre-planned events. Pre-meetings are held to discuss topics, speakers, time restraints, and holiday events.

Moms have volunteered to be coordinators of the group-making reminder calls, coordinating decorations, and sending birthday cards, and they rotate duties every three months. Speakers have conducted workshops on self-esteem, bullying, domestic violence, nutrition, and parenting as well as partici-

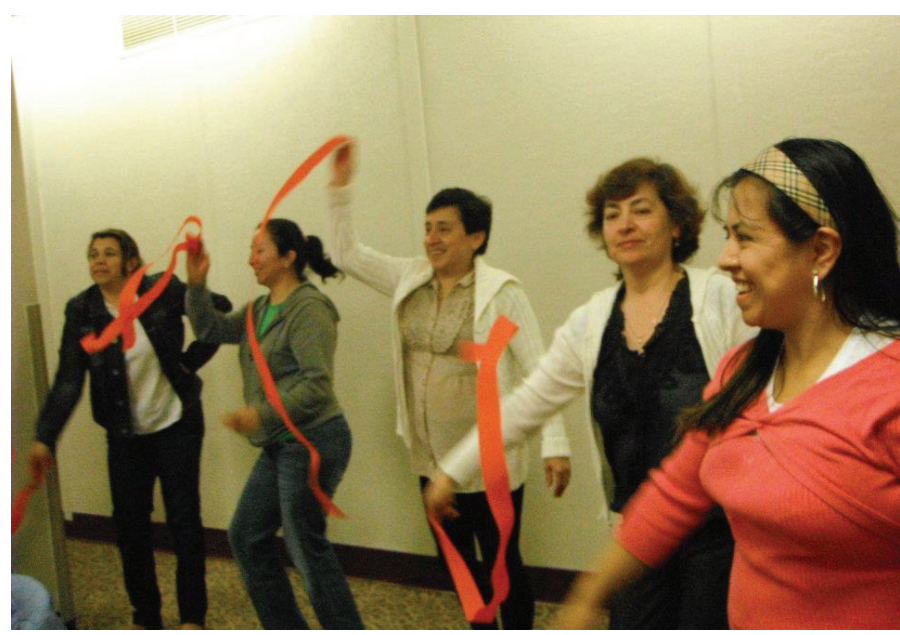

Moms dancing and learning about nutrition and healthy habits. Speaker from Cornell Cooperative Extension, December 2013.

pating in the neighborhood community garden.

The group has become well known in the community; in fact, speakers often approach us about presenting to the group. Upcoming workshops will focus on community health programs and services, keeping kids emotionally healthy, discipline and behavior management, and avoiding financial meltdowns.

The amazing connection the group has achieved can be measured by the amount of support they have offered to each other. Recently, one of the group members lost her mother and did not have the resources to attend the funeral. Several moms visited her home to let her know they were available to support her family spiritually.

Several moms have told us they feel empowered by the information they have accessed in the group. They have shared their hardship stories of coming to America, asked each other in a public forum how to deal with personal issues, cried and hugged each other, and become stronger moms, wives, and friends.

In this group, the moms have found a community center where they look for the resources to deal with daily life. They have found their voices and obtained hope to succeed in their personal endeavors. And what better place than the library to foster all this goodwill? \& 